\title{
A estrutura fundiária dos principais municípios canavieiros do Paraná: uma análise comparativa (1995-2006)
}

\author{
Jonhey Nazario Lucizani* \\ Rejane Aparecida Bianchini** \\ Werner Engel $^{* * *}$ \\ Pery Francisco Assis Shikida***
}

RESUMO - Este artigo analisa, a partir dos índices de Gini e Theil, a estrutura fundiária nos principais municípios canavieiros paranaenses em 1995 e 2006 (foram analisados ao todo 141 municípios canavieiros). Como corolário, quando mensurado o índice de Gini, houve aumento da concentração fundiária em 94 municípios canavieiros paranaenses; quando mensurado o índice de Theil, a concentração fundiária aumentou em 103 municípios. De modo geral, pode-se afirmar que a cana-de-açúcar contribuiu para o recrudescimento da concentração fundiária no estado do Paraná. Este fato está diretamente relacionado com o forte ímpeto econômico que esta atividade produtiva vem tendo no mercado, nacional e internacional, de açúcar e etanol.

Palavras-chave: Cana-de-açúcar. Estrutura fundiária. Paraná.

\section{INTRODUÇÃO}

O processo histórico de colonização brasileiro proporcionou uma distribuição desigual no território. Essa divisão territorial passou por diversos conflitos, conflitos estes que objetivavam uma melhor distribuição das terras e maiores oportunidades de acesso a ela (MORISSAWA, 2001). O que se constatou, entretanto, foi o alargamento da distância entre o pequeno e o grande produtor. Contudo, a agropecuária brasileira tem apresentado índices elevados de produtividade e, apesar da configuração atual da estrutura fundiária, o setor agropecuário avança e detém importante status no cenário econômico do país (BACHA, 2004).

Os estados brasileiros, apesar de apresentarem características diferenciadas, têm con-

\footnotetext{
* Graduado em Matemática pela Universidade Estadual do Oeste do Paraná. É mestrando em Desenvolvimento Regional e Agronegócio pela Universidade Estadual do Oeste do Paraná. Endereço eletrônico: jonheynazario@ hotmail.

${ }^{* *}$ Graduada em Geografia. É mestranda em Desenvolvimento Regional e Agronegócio pela Universidade Estadual do Oeste do Paraná. Endereço eletrônico: regibianchini@hotmail.

*** Graduado em Economia pela Faculdade Católica de Administração e Economia. É mestrando em Desenvolvimento Regional e Agronegócio pela Universidade Estadual do Oeste do Paraná. Endereço eletrônico: wernerengel@hotmail.

**** Doutor em Economia Aplicada pela Escola Superior de Agricultura Luiz de Queiroz/Universidade de São Paulo. É professor associado da Universidade Estadual do Oeste do Paraná. Endereço eletrônico: peryshikida@ hotmail.com.
} 
tribuído para o sucesso da integração nacional da agropecuária e da sua inserção no mercado mundial (CONTI, 1998). Dentre os estados, o Paraná é reconhecido, nacionalmente, como um grande produtor agrícola e hodiernamente presencia uma fase de grandes transformações no setor. O que se percebe, por parte do governo e da iniciativa privada, é que o Paraná passou a ser merecedor da adoção de uma série de medidas com o objetivo de fortalecer a agroindústria, integrando produtores de todas as regiões do estado, gerando oportunidades e divisas, graças às receitas oriundas do agronegócio (SCHMIDTKE, 2007).

Ocorre, porém, que esse modelo de agronegócio apresenta problemas que salientam as diferenças no campo paranaense, mas, por outro, proporciona a expansão das culturas destinadas à exportação. Dentre essas culturas, a cana-de-açúcar vem se destacando, fazendo-se notável quanto ao aumento da produção, notadamente de açúcar e etanol (RISSARDI JR., 2005).

Nesse contexto, o objetivo deste trabalho é analisar, a partir dos índices de Gini e Theil, a estrutura fundiária nos principais municípios canavieiros paranaenses em 1995 e 2006, fazendo-o com base nas informações dos Censos Agropecuários. Para tanto, o presente estudo está dividido em quatro partes, incluindo esta introdução. Na sequência tem-se o instrumental metodológico a ser aplicado para os municípios que possuem as maiores extensões de área plantada com a cultura de cana-de-açúcar (Seção 2). Os resultados e discussões estão na Seção 3. Finaliza-se o artigo com algumas considerações conclusivas (Seção 4).

\section{METODOLOGIA}

Qual foi a evolução fundiária nos municípios canavieiros do Paraná entre 1995 e 2006 ? Com vistas a responder a essa pergunta, serão utilizados os dados dos Censos Agropecuários e dois índices, de Gini e de Theil, gerados pela quantidade e pelo dimensionamento dos estabelecimentos agropecuários por município.

\subsection{MATERIAL}

Segundo o IBGE (2010), o conceito de estabelecimento agropecuário é “[...] todo terreno de área contínua, independente do tamanho ou situação (urbana ou rural), formado de uma ou mais parcelas, subordinado a um único produtor, onde se processe uma exploração agropecuária”.

Partindo dessa definição, esses estabelecimentos agropecuários são classificados em categorias, categorização essa visando explicitar a estrutura fundiária de uma região, do país ou, como neste estudo, do estado do Paraná, para isso se utilizando das informações dos Censos Agropecuários de 1995/96 e 2006. 
Os dados de dimensionamento e de quantidade dos estabelecimentos agropecuários estão descritos em 10 estratos de área, por hectare (ha), $\{[0,5),[5,10),[10,20),[20,50),[50,100)$, $[100,200),[200,500),[500,1000),[1000,2500)$ e $[2500,10000)\}$.

As análises da estrutura fundiária do Paraná e das áreas plantadas de cana-de-açúcar serão apresentadas por municípios, sendo utilizadas as configurações municipais anteriores a 1997 (visto que, nesse ano, foram emancipados 28 municípios no Paraná). Para efeito da análise, os dados no período estão configurados nos municípios emancipados anteriormente a 1997, quantificados em 371 municípios.

\subsection{MÉTODOS}

Neste trabalho estimam-se índices de concentração ou de desigualdade da posse de terras no Paraná. Nesse sentido, optou-se por empregar o cálculo do índice de Gini e o de Theil, visto que são medidas de dispersão relativas. Maiores considerações sobre o processo de cálculo e outras especificidades desses índices, ver: Hoffmann (1990,1998) e Câmara (1949) - neste caso para interpretação do índice de Gini para posse de estabelecimentos agropecuários. Salienta-se que o índice de Gini é mais sensível à transferências regressivas na faixa com maior densidade de frequência, em torno da mediana ou da moda da distribuição, enquanto o T de Theil é mais sensível à transferências regressivas na parte superior da distribuição (HOFFMANN, 1990).

\section{ESTRUTURA FUNDIÁRIA DO ESTADO DO PARANÁ, 1995-2006}

A cultura da cana-de-açúcar detinha, em 2006, a quinta maior área ocupada das culturas temporárias no Paraná, ficando atrás da soja, milho, trigo e feijão. Nesse contexto, ocupava 4,78\% (432.815 ha) da área plantada com as culturas temporárias, mas apresentou um acréscimo de 32,41\% de participação, do início ao fim do período analisado, 1995-2006 (IPARDES, 2010).

No Paraná nota-se que, das variações anuais de área plantada com as principais culturas temporárias supracitadas (Gráfico 1), somente a da cana-de-açúcar apresenta uma característica mais uniforme, enquanto que as outras culturas oscilaram bastante quanto à área ocupada.

Com a utilização do instrumental metodológico, evidenciou-se que a estrutura fundiária do Paraná apresentou uma concentração forte a muito forte de posse de terras, em 19952006. O índice de Gini elevou-se de 0,739 para 0,752, apresentando um acréscimo de 1,76\%, e o índice de Theil elevou-se de 0,764 para 0,796, um acréscimo de 4,19\%. Esses dados relatam uma maior concentração de posse de terras na parte superior da distribuição do que no entorno da moda da distribuição. 
GRÁFICO 1 - VARIAÇÃO DA ÁREA PLANTADA COM AS PRINCIPAIS CULTURAS TEMPORÁRIAS NO PARANÁ, 1995-2006

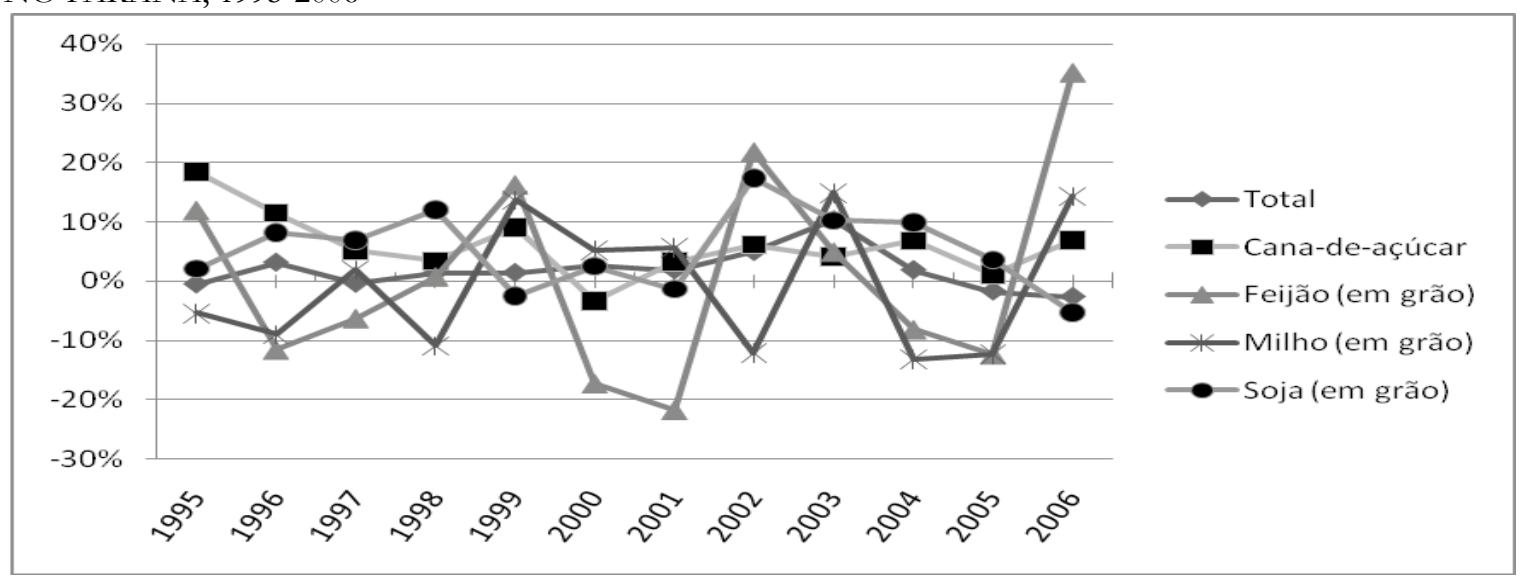

FONTE: Elaboração própria a partir de dados básicos do IBGE (2010).

A cultura de cana-de-açúcar no estado apresentou um aumento na área colhida de 285.147 ha para 432.815 ha, um acréscimo de 52\% em 1995-2006. Desse total, 98,72\% (ou 427.272 ha) concentrou-se em 141 municípios com área plantada maior ou igual a 150 hectares. Dessa forma, a abrangência do estudo delimitou-se em 141 municípios canavieiros no Paraná.

Como a área plantada do município é composta por culturas temporárias e permanentes, usando o índice de Gini, tem-se que 30\% da área ocupada com cana pode influenciar na concentração fraca a média no município. Os municípios que atendem tal classificação (concentração da atividade dentre as demais culturas) podem ser identificados na Tabela 1.

TABELA 1 - PARTICIPAÇÃO DA CULTURA DE CANA-DE-AÇÚCAR NA ÁREA PLANTADA DOS MUNICÍPIOS CANAVIEIROS DO PARANÁ (CONCENTRAÇÃO DA ATIVIDADE DENTRE AS DEMAIS CULTURAS), 1995-2006

\begin{tabular}{|c|c|c|c|c|c|c|c|}
\hline \multirow{3}{*}{ Município } & \multicolumn{4}{|c|}{ Área plantada (ha) } & \multirow{2}{*}{\multicolumn{2}{|c|}{$\begin{array}{c}\text { Participação da cana- } \\
\text { de-açúcar na área } \\
\text { plantada }(\%)\end{array}$}} & \multirow{3}{*}{\begin{tabular}{|l}
$\begin{array}{c}\text { Variação } \\
\text { de partici- } \\
\text { pação }(\%)\end{array}$ \\
$1995-2006$ \\
\end{tabular}} \\
\hline & \multicolumn{2}{|c|}{ Cana-de-açúcar } & \multicolumn{2}{|c|}{ Demais culturas** } & & & \\
\hline & 1995 & 2006 & 1995 & 2005 & 1995 & 2006 & \\
\hline Bom Sucesso & 4.731 & 6.042 & 11.090 & 11.643 & $42,66 \%$ & $51,89 \%$ & $27,71 \%$ \\
\hline Cafeara & 0 & 2.541 & 2.749 & 7.911 & $0,00 \%$ & $32,12 \%$ & * \\
\hline Cafezal do Sul & 943 & 2.596 & 5.016 & 7.785 & $18,80 \%$ & $33,35 \%$ & $175,29 \%$ \\
\hline Cambará & 13.000 & 14.000 & 43.530 & 42.733 & $29,86 \%$ & $32,76 \%$ & $7,69 \%$ \\
\hline Centenário do Sul & 7.230 & 6.056 & 13.371 & 13.580 & $54,07 \%$ & $44,59 \%$ & $-16,24 \%$ \\
\hline Cidade Gaúcha & 4.462 & 8.841 & 6.929 & 11.464 & $64,40 \%$ & $77,12 \%$ & $98,14 \%$ \\
\hline Colorado & 5.118 & 11.585 & 8.722 & 14.578 & $58,68 \%$ & $79,47 \%$ & $126,36 \%$ \\
\hline Cruzeiro do Oeste & 3.516 & 9.739 & 11.822 & 17.920 & $29,74 \%$ & $54,35 \%$ & $176,99 \%$ \\
\hline Cruzeiro do Sul & 2.958 & 5.674 & 5.703 & 11.962 & $51,87 \%$ & $47,43 \%$ & $91,82 \%$ \\
\hline Diamante do Norte & 896 & 1.771 & 5.162 & 3.952 & $17,36 \%$ & $44,81 \%$ & $97,66 \%$ \\
\hline Florestópolis & 4.674 & 5.399 & 12.034 & 15.908 & $38,84 \%$ & $33,94 \%$ & $15,51 \%$ \\
\hline Flórida & 1.194 & 1.631 & 2.584 & 4.542 & $46,21 \%$ & $35,91 \%$ & $36,60 \%$ \\
\hline Guaporema & 1.941 & 4.339 & 3.668 & 5.922 & $52,92 \%$ & $73,27 \%$ & $123,54 \%$ \\
\hline Icaraíma & 2.670 & 8.259 & 6.164 & 15.382 & $43,32 \%$ & $53,69 \%$ & $209,33 \%$ \\
\hline Inajá & 0 & 4.343 & 2.222 & 4.771 & $0,00 \%$ & $91,03 \%$ & $*$ \\
\hline Indianópolis & 986 & 2.710 & 3.663 & 5.092 & $26,92 \%$ & $53,22 \%$ & $174,85 \%$ \\
\hline
\end{tabular}


TABELA 1 - (CONTINUAÇÃO) PARTICIPAÇÃO DA CULTURA DE CANA-DE-AÇÚCAR NA ÁREA PLANTADA DOS MUNICÍPIOS CANAVIEIROS DO PARANÁ (CONCENTRAÇÃO DA ATIVIDADE DENTRE AS DEMAIS CULTURAS), 1995-2006

\begin{tabular}{|c|c|c|c|c|c|c|c|}
\hline \multirow{3}{*}{ Município } & \multicolumn{4}{|c|}{ Área plantada (ha) } & \multirow{2}{*}{\multicolumn{2}{|c|}{$\begin{array}{c}\text { Participação da cana- } \\
\text { de-açúcar na área } \\
\text { plantada }(\%)\end{array}$}} & \multirow{3}{*}{\begin{tabular}{|l|}
$\begin{array}{l}\text { Variação } \\
\text { de partici- } \\
\text { pação }(\%)\end{array}$ \\
$1995-2006$ \\
\end{tabular}} \\
\hline & \multicolumn{2}{|c|}{ Cana-de-açúcar } & \multicolumn{2}{|c|}{ Demais culturas** } & & & \\
\hline & 1995 & 2006 & 1995 & 2005 & 1995 & 2006 & \\
\hline Itaguajé & 0 & 1.039 & 1.912 & 3.353 & $0,00 \%$ & $30,99 \%$ & . \\
\hline Itaúna do Sul & 271 & 612 & 3.433 & 1.763 & $7,89 \%$ & $34,71 \%$ & $125,83 \%$ \\
\hline Ivaté & 3.550 & 12.914 & 6.805 & 14.139 & $52,17 \%$ & $91,34 \%$ & $263,77 \%$ \\
\hline Jacarezinho & 14.000 & 24.000 & 24.768 & 29.632 & $56,52 \%$ & $80,99 \%$ & $71,43 \%$ \\
\hline Lobato & 4.097 & 7.347 & 6.357 & 14.568 & $64,45 \%$ & $50,43 \%$ & $79,33 \%$ \\
\hline Mandaguaçu & 4.548 & 7.800 & 14.655 & 24.633 & $31,03 \%$ & $31,66 \%$ & $71,50 \%$ \\
\hline Marilena & 882 & 3.785 & 5.336 & 6.620 & $16,53 \%$ & $57,18 \%$ & $329,14 \%$ \\
\hline Marumbi & 1.128 & 2.835 & 6.775 & 7.926 & $16,65 \%$ & $35,77 \%$ & $151,33 \%$ \\
\hline Miraselva & 1.949 & 1.305 & 9.176 & 2.304 & $21,24 \%$ & $56,64 \%$ & $-33,04 \%$ \\
\hline Nossa Senhora das Graças & 3.320 & 5.730 & 4.531 & 9.252 & $73,27 \%$ & $61,93 \%$ & $72,59 \%$ \\
\hline Nova Aliança do Ivaí & 12 & 1.197 & 513 & 2.309 & $2,34 \%$ & $51,84 \%$ & $9875,00 \%$ \\
\hline Nova Londrina & 2.068 & 3.521 & 3.929 & 5.443 & $52,63 \%$ & $64,69 \%$ & $70,26 \%$ \\
\hline Nova Olímpia & 557 & 771 & 3.303 & 2.159 & $16,86 \%$ & $35,71 \%$ & $38,42 \%$ \\
\hline Paraíso do Norte & 2.311 & 6.558 & 5.335 & 10.282 & $43,32 \%$ & $63,78 \%$ & $183,77 \%$ \\
\hline Paranacity & 4.805 & 14.720 & 8.550 & 18.068 & $56,20 \%$ & $81,47 \%$ & $206,35 \%$ \\
\hline Porecatu & 10.318 & 9.656 & 14.597 & 14.129 & $70,69 \%$ & $68,34 \%$ & $-6,42 \%$ \\
\hline Presidente Castelo Branco & 3.464 & 3.500 & 5.526 & 6.668 & $62,69 \%$ & $52,49 \%$ & $1,04 \%$ \\
\hline Rondon & 8.864 & 15.220 & 12.928 & 18.403 & $68,56 \%$ & $82,70 \%$ & $71,71 \%$ \\
\hline Santo Inácio & 564 & 2.448 & 4.058 & 6.094 & $13,90 \%$ & $40,17 \%$ & $334,04 \%$ \\
\hline São Carlos do Ivaí & 5.133 & 8.803 & 8.323 & 13.615 & $61,67 \%$ & $64,66 \%$ & $71,50 \%$ \\
\hline São João do Caiuá & 557 & 1.639 & 3.064 & 3.691 & $18,18 \%$ & $44,41 \%$ & $194,25 \%$ \\
\hline São Pedro do Ivaí & 6.350 & 8.117 & 23.723 & 22.853 & $26,77 \%$ & $35,52 \%$ & $27,83 \%$ \\
\hline São Tomé & 5.405 & 9.311 & 11.605 & 15.486 & $46,57 \%$ & $60,13 \%$ & $72,27 \%$ \\
\hline Tamboara & 923 & 3.456 & 3.625 & 6.235 & $25,46 \%$ & $55,43 \%$ & $274,43 \%$ \\
\hline Tapejara & 3.100 & 13.850 & 7.843 & 17.148 & $39,53 \%$ & $80,77 \%$ & $346,77 \%$ \\
\hline Tapira & 786 & 3.049 & 5.980 & 7.146 & $13,14 \%$ & $42,67 \%$ & $287,91 \%$ \\
\hline Tuneiras do Oeste & 3.435 & 9.160 & 10.761 & 30.261 & $31,92 \%$ & $30,27 \%$ & $166,67 \%$ \\
\hline Uniflor & 459 & 1.267 & 2.157 & 3.816 & $21,28 \%$ & $33,20 \%$ & $176,03 \%$ \\
\hline
\end{tabular}

FONTE: Elaboração própria, a partir de dados do IBGE (2010).

NOTA: *Não se aplica quando o município não tinha a cultura inserida em 1995; **Demais culturas incluem culturas temporárias e permanentes.

Esplanadas as devidas ressalvas, alerta-se que o índice de Gini foi calculado para os 141 municípios canavieiros, mas para a composição da análise foram utilizados também os dados de participação de área plantada dos municípios, conforme a Tabela 1. O ano-base utilizado para a classificação foi 2006, relacionando com os dados de 1995.

Isto posto, na sequência serão apresentadas as concentrações de fraca a média (Tabela 2), média a forte (Tabela 3) e forte a muito forte (Tabela 4), no tocante à posse de terra nos principais municípios canavieiros paranaenses.

Conforme os dados auferidos na Tabela 2, observa-se que 5 municípios canavieiros apresentaram concentração fraca a média, possuindo 3.840 ha de área plantada em 2006, evidenciando um aumento de 241\% em relação a 1995. 
TABELA 2 - CONCENTRAÇÃO FRACA A MÉDIA DE POSSE DE TERRA NOS PRINCIPAIS MUNICÍPIOS CANAVIEIROS PARANAENSES, 1995-2006

\begin{tabular}{|c|c|c|c|c|c|c|c|c|c|}
\hline \multirow{2}{*}{ Localidade } & \multicolumn{3}{|c|}{ Índice de Gini } & \multicolumn{3}{|c|}{ Índice de Theil } & \multicolumn{3}{|c|}{ Área plantada (hectare) } \\
\hline & 1995 & 2006 & $\operatorname{Var}(\%)$ & 1995 & 2006 & $\operatorname{Var}(\%)$ & 1995 & 2006 & $\operatorname{Var}(\%)$ \\
\hline Capanema & 0,441 & 0,355 & $-19,50 \%$ & 0,337 & 0,344 & $2,08 \%$ & 50 & 180 & $260,00 \%$ \\
\hline Flor da Serra do Sul & 0,411 & 0,443 & $7,79 \%$ & 0,316 & 0,421 & $33,23 \%$ & 10 & 180 & $1700,00 \%$ \\
\hline Francisco Beltrão & 0,458 & 0,443 & $-3,28 \%$ & 0,442 & 0,415 & $-6,11 \%$ & 60 & 550 & $816,67 \%$ \\
\hline Indianópolis & 0,541 & 0,442 & $-18,30 \%$ & 0,450 & 0,476 & $5,78 \%$ & 986 & 2710 & $174,85 \%$ \\
\hline Marmeleiro & 0,524 & 0,436 & $-16,79 \%$ & 0,524 & 0,432 & $-17,56 \%$ & 20 & 220 & $1000,00 \%$ \\
\hline
\end{tabular}

FONTE: Dados básicos do Censo Agropecuário (1995/96 e 2006) trabalhados na pesquisa.

Desse conjunto de municípios, Indianópolis apresentou índice de Gini de 0,541 em 1995 e 0,442 em 2006, uma variação negativa na concentração de posse de terras em 18,30\%. Já o índice de Theil em 1995 foi de 0,450, e 0,476 em 2006, resultando num crescimento de concentração na parte superior da distribuição de 5,78\%. Por outro lado, no município de Marmeleiro, ambos os índices apresentaram variação negativa de $16,79 \%$ no índice de Gini $(0,524$ em 1995 para 0,436 em 2006), e de 17,56\% no índice de Theil (0,524 em 1995 para 0,432 em 2006), indicando desconcentração na faixa superior e no entorno da moda da distribuição dos estratos de terras.

Na Tabela 3, dos 69 municípios canavieiros que possuem concentração fundiária de média a forte, existem 13 municípios com indústrias sucroalcooleiras (em itálico), dos quais 5 municípios (Rondon, São Tomé, Santo Inácio, São Pedro do Ivaí e Cambará), em 2006, possuíam participação superior a 30\% de cultura da cana-de-açúcar na área total plantada no município, variando de 32,76\% a 82,70\%. Já em relação a 1995, a participação na área plantada de cana-de-açúcar nesses municípios variava de 13,90\% a 68,56\% (conforme dados apresentados na Tabela 1).

TABELA 3 - CONCENTRAÇÃO MÉDIA A FORTE DE POSSE DE TERRA NOS PRINCIPAIS MUNICÍPIOS CANAVIEIROS PARANAENSES, 1995-2006

\begin{tabular}{|c|c|c|c|c|c|c|c|c|c|}
\hline \multirow{2}{*}{ Localidade } & \multicolumn{3}{|c|}{ Indice de Gini } & \multicolumn{3}{|c|}{ Indice de Theil } & \multicolumn{3}{|c|}{ Área plantada (hectare) } \\
\hline & 1995 & 2006 & $\operatorname{Var}(\%)$ & 1995 & 2006 & $\operatorname{Var}(\%)$ & 1995 & 2006 & $\operatorname{Var}(\%)$ \\
\hline$\overline{\text { Abatiá }}$ & 0,542 & 0,551 & $1,66 \%$ & 0,470 & 0,547 & $16,38 \%$ & 1000 & 400 & $-60,00 \%$ \\
\hline Alto Paraná & 0,582 & 0,669 & $14,95 \%$ & 0,521 & 0,612 & $17,47 \%$ & 100 & 1442 & $1342,00 \%$ \\
\hline Alvorada do Sul & 0,693 & 0,696 & $0,43 \%$ & 0,643 & 0,666 & $3,58 \%$ & 1907 & 2311 & $21,19 \%$ \\
\hline Anahy & 0,454 & 0,539 & $18,72 \%$ & 0,374 & 0,462 & $23,53 \%$ & 100 & 150 & $50,00 \%$ \\
\hline Barracão & 0,518 & 0,536 & $3,47 \%$ & 0,451 & 0,581 & $28,82 \%$ & 30 & 310 & $933,33 \%$ \\
\hline Barra do Jacaré & 0,605 & 0,604 & $-0,17 \%$ & 0,527 & 0,572 & $8,54 \%$ & 1100 & 2100 & $90,91 \%$ \\
\hline Bituruna & 0,598 & 0,604 & $1,00 \%$ & 0,658 & 0,608 & $-7,60 \%$ & 0 & 150 & * \\
\hline Boa Vista da Aparecida & 0,486 & 0,534 & $9,88 \%$ & 0,375 & 0,51 & $36,00 \%$ & 50 & 200 & $300,00 \%$ \\
\hline Bom Sucesso & 0,677 & 0,691 & $2,07 \%$ & 0,561 & 0,62 & $10,52 \%$ & 4731 & 6042 & $27,71 \%$ \\
\hline Cafeara & 0,678 & 0,657 & $-3,10 \%$ & 0,628 & 0,644 & $2,55 \%$ & $\mathbf{0}$ & 2541 & * \\
\hline Cambará & 0,571 & 0,581 & $1,75 \%$ & 0,478 & 0,584 & $22,18 \%$ & 13000 & 14000 & $7,69 \%$ \\
\hline Cambira & 0,512 & 0,582 & $13,67 \%$ & 0,396 & 0,534 & $34,85 \%$ & 188 & 553 & $194,15 \%$ \\
\hline Capitão Leônidas Marques & 0,453 & 0,530 & $17,00 \%$ & 0,344 & 0,558 & $62,21 \%$ & 100 & 1000 & $900,00 \%$ \\
\hline Catanduvas & 0,693 & 0,689 & $-0,58 \%$ & 0,64 & 0,64 & $0,00 \%$ & 30 & 1300 & $4233,33 \%$ \\
\hline Céu Azul & 0,652 & 0,67 & $2,76 \%$ & 0,6 & 0,644 & $7,33 \%$ & 30 & 530 & $1666,67 \%$ \\
\hline Corbélia & 0,590 & 0,648 & $9,83 \%$ & 0,511 & 0,559 & $9,39 \%$ & 70 & 1000 & $1328,57 \%$ \\
\hline
\end{tabular}


TABELA 3 - (CONTINUAÇÃO) CONCENTRAÇÃO MÉDIA A FORTE DE POSSE DE TERRA NOS PRINCIPAIS MUNICÍPIOS CANAVIEIROS PARANAENSES, 1995-2006

\begin{tabular}{|c|c|c|c|c|c|c|c|c|c|}
\hline \multirow{2}{*}{ Localidade } & \multicolumn{3}{|c|}{ Indice de Gini } & \multicolumn{3}{|c|}{ Indice de Theil } & \multicolumn{3}{|c|}{ Área plantada (hectare) } \\
\hline & 1995 & 2006 & Var (\%) & 1995 & 2006 & Var (\%) & 1995 & 2006 & $\operatorname{Var}(\%)$ \\
\hline Cornélio Procópio & 0,700 & 0,693 & $-1,00 \%$ & 0,644 & 0,656 & $1,86 \%$ & 800 & 1170 & $46,25 \%$ \\
\hline Cruzeiro do Sul & 0,678 & 0,684 & $0,88 \%$ & 0,392 & 0,645 & $64,54 \%$ & 2958 & 5674 & $91,82 \%$ \\
\hline Dois Vizinhos & 0,491 & 0,533 & $8,55 \%$ & 0,402 & 0,524 & $30,35 \%$ & 100 & 230 & $130,00 \%$ \\
\hline Fênix & 0,635 & 0,643 & $1,26 \%$ & 0,555 & 0,558 & $0,54 \%$ & 1438 & 2320 & $61,34 \%$ \\
\hline Floraí & 0,591 & 0,515 & $-12,86 \%$ & 0,481 & 0,385 & $-19,96 \%$ & 523 & 1700 & $225,05 \%$ \\
\hline Flórida & 0,631 & 0,67 & $6,18 \%$ & 0,297 & 0,583 & $96,30 \%$ & 1194 & 1631 & $36,60 \%$ \\
\hline Guaporema & 0,613 & 0,639 & $4,24 \%$ & 0,384 & 0,541 & $40,89 \%$ & 1941 & 4339 & $123,54 \%$ \\
\hline Iporã & 0,552 & 0,68 & $23,19 \%$ & 0,483 & 0,675 & $39,75 \%$ & 0 & 1057 & * \\
\hline Itaguajé & 0,653 & 0,539 & $-17,46 \%$ & 0,592 & 0,56 & $-5,41 \%$ & 0 & 1039 & * \\
\hline Itam & 0,653 & 0,687 & $5,21 \%$ & 0,672 & 0,652 & $-2,98 \%$ & 3800 & 2100 & $-44,74 \%$ \\
\hline Itambé & 0,564 & 0,653 & $15,78 \%$ & 0,443 & 0,572 & $29,12 \%$ & 2796 & 2010 & $-28,11 \%$ \\
\hline Ivaiporã & 0,567 & 0,645 & $13,76 \%$ & 0,558 & 0,653 & $17,03 \%$ & 1000 & 320 & $-68,00 \%$ \\
\hline Jaboti & 0,525 & 0,61 & $16,19 \%$ & 0,445 & 0,539 & $21,12 \%$ & 30 & 200 & $566,67 \%$ \\
\hline Jandaia $d$ & 0,46 & 0,684 & $48,70 \%$ & 0,359 & 0,688 & $91,64 \%$ & 1644 & 2655 & $61,50 \%$ \\
\hline Japurá & 0,528 & 0,506 & $-4,17 \%$ & 0,438 & 0,454 & $3,65 \%$ & 1540 & 1660 & $7,79 \%$ \\
\hline Jussara & 0,605 & 0,614 & $1,49 \%$ & 0,675 & 0,563 & $-16,59 \%$ & 2900 & 3350 & $15,52 \%$ \\
\hline Kaloré & 0,565 & 0,548 & $-3,01 \%$ & 0,474 & 0,501 & $5,70 \%$ & 581 & 684 & $17,73 \%$ \\
\hline Lindoest & 0,712 & 0,694 & $-2,53 \%$ & 0,747 & 0,759 & $1,61 \%$ & 30 & 200 & $566,67 \%$ \\
\hline Lobato & 0,663 & 0,531 & $-19,91 \%$ & 0,168 & 0,415 & $147,02 \%$ & 4097 & 7347 & $79,33 \%$ \\
\hline Lup & 0,751 & 0,688 & $-8,39 \%$ & 0,753 & 0,729 & $-3,19 \%$ & 0 & 465 & . \\
\hline Mand & 0,706 & 0,672 & $-4,82 \%$ & 0,777 & 0,627 & $-19,31 \%$ & 4548 & 7800 & $71,50 \%$ \\
\hline Mand & 0,603 & 0,662 & $9,78 \%$ & 0,514 & 0,627 & $21,98 \%$ & 430 & 1160 & $169,77 \%$ \\
\hline $\mathrm{Ma}$ & 0,654 & 0,681 & $4,13 \%$ & 0,611 & 0,659 & $7,86 \%$ & 82 & 650 & $692,68 \%$ \\
\hline Mar & 0,731 & 0,622 & $-14,91 \%$ & 0,715 & 0,657 & $-8,11 \%$ & 882 & 3785 & $329,14 \%$ \\
\hline Mari & 0,597 & 0,696 & $16,58 \%$ & 0,509 & 0,626 & $22,99 \%$ & 1290 & 1480 & $14,73 \%$ \\
\hline M & 0,613 & 0,649 & $5,87 \%$ & 0,547 & 0,621 & $13,53 \%$ & 15 & 320 & $2033,33 \%$ \\
\hline Mira & 0,768 & 0,678 & $-11,72 \%$ & 0,666 & 0,593 & $-10,96 \%$ & 705 & 2433 & $245,11 \%$ \\
\hline Mor & 0,642 & 0,629 & $-2,02 \%$ & 0,676 & 0,623 & $-7,84 \%$ & 4500 & 6500 & $44,44 \%$ \\
\hline & 0,687 & 0,699 & $1,75 \%$ & 0,609 & 0,645 & $5,91 \%$ & 663 & 2264 & $241,48 \%$ \\
\hline No & 0,586 & 0,64 & $9,22 \%$ & 0,477 & 0,532 & $11,53 \%$ & 12 & 1197 & $9875,00 \%$ \\
\hline No & 0,623 & 0,616 & $-1,12 \%$ & 0,634 & 0,59 & $-6,94 \%$ & 700 & 970 & $38,57 \%$ \\
\hline Nova Aurora & 0,527 & 0,518 & $-1,71 \%$ & 0,46 & 0,479 & $4,13 \%$ & 0 & 150 & * \\
\hline No & 0,628 & 0,601 & $-4,30 \%$ & 0,489 & 0,551 & $12,68 \%$ & 1341 & 2800 & $108,80 \%$ \\
\hline $\mathrm{Ou}$ & 0,549 & 0,564 & $2,73 \%$ & 0,423 & 0,485 & $14,66 \%$ & 747 & 1250 & $67,34 \%$ \\
\hline & 0,645 & 0,52 & $-19,38 \%$ & 0,646 & 0,416 & $-35,60 \%$ & 1187 & 2600 & $119,04 \%$ \\
\hline & 0,637 & 0,681 & $6,91 \%$ & 0,527 & 0,666 & $26,38 \%$ & 4 & 180 & $4400,00 \%$ \\
\hline Per & 0,682 & 0,664 & $-2,64 \%$ & 0,639 & 0,602 & $-5,79 \%$ & 253 & 300 & $18,58 \%$ \\
\hline Pitangu & 0,643 & 0,659 & $2,49 \%$ & 0,603 & 0,608 & $0,83 \%$ & 188 & 424 & $125,53 \%$ \\
\hline Rolândia & 0,548 & 0,539 & $-1,64 \%$ & 0,435 & 0,478 & $9,89 \%$ & 4061 & 4490 & $10,56 \%$ \\
\hline Rondon & 0,696 & 0,695 & $-0,14 \%$ & 0,617 & 0,617 & $0,00 \%$ & 8864 & 15220 & $71,71 \%$ \\
\hline & 0,487 & 0,585 & $20,12 \%$ & 0,451 & 0,6 & $33,04 \%$ & 40 & 290 & $625,00 \%$ \\
\hline San & 0,631 & 0,67 & $6,18 \%$ & 0,176 & 0,621 & $252,84 \%$ & 0 & 150 & 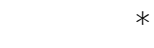 \\
\hline Santa Inês & 0,628 & 0,534 & $-14,97 \%$ & 0,507 & 0,439 & $-13,41 \%$ & 273 & 668 & $144,69 \%$ \\
\hline Santo 1 & 0,678 & 0,691 & $1,92 \%$ & 0,635 & 0,701 & $10,39 \%$ & 1100 & 2800 & $154,55 \%$ \\
\hline Santo Inácio & 0,592 & 0,633 & $6,93 \%$ & 0,479 & 0,556 & $16,08 \%$ & 564 & 2448 & $334,04 \%$ \\
\hline São João do Ivaí & 0,579 & 0,645 & $11,40 \%$ & 0,502 & 0,626 & $24,70 \%$ & 1600 & 1652 & $3,25 \%$ \\
\hline São Jorge & 0,585 & 0,555 & $-5,13 \%$ & 0,479 & 0,446 & $-6,89 \%$ & 484 & 320 & $-33,88 \%$ \\
\hline São Miguel do Ig & 0,626 & 0,68 & $8,63 \%$ & 0,597 & 0,649 & $8,71 \%$ & 150 & 200 & $33,33 \%$ \\
\hline São Pedro do Ivaí & 0,68 & 0,693 & $1,91 \%$ & 0,644 & 0,637 & $-1,09 \%$ & 6350 & 8117 & $27,83 \%$ \\
\hline São Tomé & 0,546 & 0,521 & $-4,58 \%$ & 0,416 & 0,5 & $20,19 \%$ & 5405 & 9311 & $72,27 \%$ \\
\hline Tamboa & 0,645 & 0,6 & $-6,98 \%$ & 0,577 & 0,551 & $-4,51 \%$ & 923 & 3456 & $274,43 \%$ \\
\hline Tapira & 0,724 & 0,696 & $-3,87 \%$ & 0,755 & 0,727 & $-3,71 \%$ & 786 & 3049 & $287,91 \%$ \\
\hline Terra Rica & 0,719 & 0,699 & $-2,78 \%$ & 0,644 & 0,64 & $-0,62 \%$ & 0 & 967 & \\
\hline
\end{tabular}

FONTE: Dados básicos do Censo Agropecuário (1995/96 e 2006) e ALCOPAR trabalhados na pesquisa.

NOTA: *Não se aplica quando o município não tinha a cultura inserida em 1995; Em itálico, município que possui 
usina e/ou destilaria.

Dentre esses 13 municípios, Rondon destaca-se por dispor, no ano de 2006, da maior participação da área plantada com cana-de-açúcar (82,70\%), possuindo, nesse ano, 15.220 ha de área plantada com a cultura, evidenciando um aumento de 6.356 ha em relação a 1995 . O município citado obteve, em 1995, o índice de Gini de 0,696 e o índice de Theil de 0,617. Em 2006, esses índices foram 0,695 e 0,617, respectivamente, apresentando uma variação pouco representativa no período. Assim, pode-se verificar que não houve mudança significativa nos índices, mas evidenciou-se uma expansão significativa da área plantada de cana-de-açúcar.

Ainda sobre a Tabela 3, foram encontrados 12 municípios (Guaporema, Marilena, Tamboara, Bom Sucesso, Nova Aliança do Ivaí, Lobato, Cruzeiro do Sul, Tapira, Flórida, Cafeara, Mandaguaçu e Itaguajé - todos em negrito) que não possuíam indústrias sucroalcooleiras em seus limites territoriais, representando $22 \%$ do total dos municípios sem indústrias instaladas, que detinham participação da cana-de-açúcar acima de 30\% do total da área plantada, variando de $31 \%$ a $73,27 \%$ em 2006 . Em relação a 1995, a participação da cana, nesses municípios, variava de $0 \%$ a $64,45 \%$.

Desses 12 municípios supracitados, Guaporema destaca-se com a maior participação da cana-de-açúcar na área total plantada no município, em 1995-2006, possuindo 4.339 ha de área plantada com a cultura, de um total de 5.922 ha em 2006, representando uma participação de 73,27\%, evidenciando um aumento de 2.398 ha em relação a 1995 . O município obteve o índice de Gini de 0,613, e o índice de Theil de 0,384 em 1995. Esses índices foram de 0,639 e 0,541, respectivamente, em 2006, apresentando uma variação de 4,24\% no índice de Gini e de 40,89\% no índice de Theil. Pode-se verificar que houve uma mudança significativa entre os grandes estabelecimentos agropecuários desse município, evidenciando a concentração fundiária média a forte em Guaporema, enquanto que na distribuição em torno da moda houve pouca mudança.

$\mathrm{Na}$ Tabela 4, o conjunto dos 67 municípios está relacionado à concentração fundiária forte a muito forte. Dentre esses, 15 possuem indústrias sucroalcooleiras (em itálico), sendo que 9 representam $60 \%$ do total das indústrias, instaladas em 8 municípios, com participação superior a 30\% da área plantada com a cultura da cana-de-açúcar, variando de 33,94\% a 91,34\% em 2006. Em relação a 1995, houve uma participação na área plantada, variando de 38,84\% a 70,69\% nesses mesmos municípios.

No contexto da concentração forte a muito forte, Ivaté destaca-se com maior participação da área plantada de cana-de-açúcar (91,34\%), possuindo 12.914 ha de área plantada 
em 2006, evidenciando um aumento de 9.364 ha em relação a 1995. Desse modo, o município obteve o índice de Gini de 0,816, e o índice de Theil de 0,851 em 1995. Em 2006, esses índices foram 0,829 e 0,839 , respectivamente, apresentando uma variação sutil no período da análise. Pode-se verificar que, mesmo diante dessa pequena variação nos índices, manteve-se a forte concentração de terras.

TABELA 4 - CONCENTRAÇÃO FORTE A MUITO FORTE DE POSSE DE TERRA NOS PRINCIPAIS MUNICÍPIOS CANAVIEIROS PARANAENSES, 1995-2006

\begin{tabular}{|c|c|c|c|c|c|c|c|c|c|}
\hline \multirow{2}{*}{ Localidade } & \multicolumn{3}{|c|}{ Índice de Gini } & \multicolumn{3}{|c|}{ Índice de Theil } & \multicolumn{3}{|c|}{ Área plantada (hectare) } \\
\hline & 1995 & 2006 & $\operatorname{Var}(\%)$ & 1995 & 2006 & $\operatorname{Var}(\%)$ & 1995 & 2006 & $\operatorname{Var}(\%)$ \\
\hline Alto Piquiri & 0,642 & 0,720 & $12,15 \%$ & 0,545 & 0,643 & $17,98 \%$ & 1696 & 3686 & $117,33 \%$ \\
\hline Andirá & 0,652 & 0,729 & $11,81 \%$ & 0,583 & 0,696 & $19,38 \%$ & 4600 & 3000 & $8 \%$ \\
\hline Astorga & 0,704 & 0,777 & $10,37 \%$ & 0,661 & 0,738 & $11,65 \%$ & 2466 & 3485 & $41,32 \%$ \\
\hline Atalaia & 0,550 & 0,732 & $33,09 \%$ & 0,438 & 0,687 & $56,85 \%$ & 0 & 300 & $*$ \\
\hline Bandeirantes & 0,628 & 0,704 & $12,10 \%$ & 0,583 & 0,697 & $19,55 \%$ & 11000 & 6300 & $-42,73 \%$ \\
\hline Barbosa Ferraz & 0,642 & 0,731 & $13,86 \%$ & 0,592 & 0,735 & $24,16 \%$ & 0 & 350 & $*$ \\
\hline Brasilândia do Sul & 0,696 & 0,701 & $0,72 \%$ & 0,589 & 0,619 & $5,09 \%$ & 333 & 150 & $-54,95 \%$ \\
\hline Cafezal do Sul & 0,726 & 0,707 & $-2,62 \%$ & 0,738 & 0,667 & $-9,62 \%$ & 943 & 2596 & $29 \%$ \\
\hline Cambé & 0,608 & 0,756 & $24,34 \%$ & 0,515 & 0,731 & $41,94 \%$ & 285 & 600 & $110,53 \%$ \\
\hline Campo Bor & 0,702 & 0,765 & $8,97 \%$ & 0,698 & 0,750 & $7,45 \%$ & 34 & 300 & $782,35 \%$ \\
\hline Cascavel & 0,704 & 0,774 & $9,94 \%$ & 0,657 & 0,769 & $5 \%$ & 50 & 550 & $1000,00 \%$ \\
\hline Centenári & 0,736 & 0,727 & $-1,22 \%$ & 0,725 & 0,686 & $-5,38 \%$ & 7230 & 6056 & $-16,24 \%$ \\
\hline Cianorte & 0,742 & 0,709 & $-4,45 \%$ & 0,868 & 0,690 & $-20,51 \%$ & 1560 & 3650 & $133,97 \%$ \\
\hline Cidade Gar & 0,681 & 0,702 & $3,08 \%$ & 0,613 & 0,627 & $2,28 \%$ & 4462 & 8841 & $98,14 \%$ \\
\hline Colorado & 0,713 & 0,712 & $-0,14 \%$ & 0,797 & 0,666 & $-16,44 \%$ & 5118 & 11585 & $126,36 \%$ \\
\hline Congonh & 0,735 & 0,788 & $7,21 \%$ & 0,648 & 0,801 & $23,61 \%$ & 500 & 1660 & $232,00 \%$ \\
\hline $\mathrm{Cor}$ & 0,732 & 0,790 & $7,92 \%$ & 0,667 & 0,780 & & 850 & 400 & $4 \%$ \\
\hline Cruzeiro & 0,728 & 0,720 & $-1,10 \%$ & 0,693 & 0,686 & $-1,01 \%$ & 3516 & 9739 & $176,99 \%$ \\
\hline Diamar & 0,729 & 0,733 & $0,55 \%$ & 0,736 & 0,708 & -3 & 896 & 1771 & $97,66 \%$ \\
\hline Dia & 0,758 & 0,723 & $-4,62 \%$ & 0,766 & 0,763 & & 10 & 180 & $1700,00 \%$ \\
\hline Dou & 0,759 & 0,803 & $5,80 \%$ & 0,752 & 0,789 & $2 \%$ & 0 & 1620 & * \\
\hline Engenheiro $B$ & 0,642 & 0,712 & $10,90 \%$ & 0,631 & 0,699 & $10,78 \%$ & 5475 & 8471 & $54,72 \%$ \\
\hline Florestópolis & 0,732 & 0,758 & $5 \%$ & 0,558 & 0,729 & 30 , & 4674 & 5399 & $15,51 \%$ \\
\hline & 0,721 & 0,764 & $5,96 \%$ & 0,682 & 0,736 & $2 \%$ & 470 & 1400 & $197,87 \%$ \\
\hline $\mathrm{Gu}$ & 0,742 & 0,779 & $4,99 \%$ & 0,655 & 0,754 & 15 , & 540 & 625 & $15,74 \%$ \\
\hline $\mathrm{Gu}$ & 0,707 & 0,718 & $1,56 \%$ & 0,636 & 0,676 & & 200 & 450 & $125,00 \%$ \\
\hline & 0,709 & 0,743 & $4,80 \%$ & 0,604 & 0,696 & $15,23 \%$ & 1121 & 258 & $-76,98 \%$ \\
\hline Ibaiti & 0,742 & 0,748 & $0,81 \%$ & 0,758 & 0,777 & $2,51 \%$ & 6500 & 5000 & $-23,08 \%$ \\
\hline Icaraíma & 0,773 & 0,738 & $-4,53 \%$ & 0,785 & 0,749 & $9 \%$ & 2670 & 8259 & $209,33 \%$ \\
\hline & 0,645 & 0,721 & $11,78 \%$ & 0,390 & 0,641 & $64,36 \%$ & 69 & 1319 & $1811,59 \%$ \\
\hline Inajá & 0,731 & 0,803 & $9,85 \%$ & 0,625 & 0,755 & $20,80 \%$ & 0 & 4343 & \\
\hline Itaún & 0,755 & 0,729 & $-3,44 \%$ & 0,681 & 0,687 & & 271 & 612 & $83 \%$ \\
\hline Ivaté & 0,816 & 0,829 & $1,59 \%$ & 0,851 & 0,839 & $-1,41 \%$ & 3550 & 12914 & $263,77 \%$ \\
\hline Jacare & 0,803 & 0,877 & $9,22 \%$ & 0,743 & 0,917 & $23,42 \%$ & 14000 & 24000 & $71,43 \%$ \\
\hline Jagr & 0,699 & 0,770 & $10,16 \%$ & 0,641 & 0,742 & $6 \%$ & 2569 & 5533 & $115,38 \%$ \\
\hline Marialva & 0,643 & 0,718 & $11,66 \%$ & 0,520 & 0,659 & $26,73 \%$ & 3086 & 3200 & $3,69 \%$ \\
\hline Mariluz & 0,824 & 0,795 & $-3,52 \%$ & 0,779 & 0,897 & $15,15 \%$ & 1628 & 3845 & $136,18 \%$ \\
\hline Marum & 0,648 & 0,726 & $12,04 \%$ & 0,621 & 0,667 & $7,41 \%$ & 1128 & 2835 & $151,33 \%$ \\
\hline Miraselva & 0,726 & 0,776 & $6,89 \%$ & 0,669 & 0,735 & $9,87 \%$ & 1949 & 3467 & $77,89 \%$ \\
\hline Nossa Se & 0,752 & 0,715 & $-4,92 \%$ & 0,291 & 0,657 & $125,77 \%$ & 3320 & 5730 & $72,59 \%$ \\
\hline Nova Fátima & 0,735 & 0,826 & $12,38 \%$ & 0,676 & 0,808 & $19,53 \%$ & 120 & 200 & $66,67 \%$ \\
\hline Nova Londrina & 0,758 & 0,733 & $-3,30 \%$ & 0,666 & 0,668 & $0,30 \%$ & 2068 & 3521 & $70,26 \%$ \\
\hline Nova Olím & 0,733 & 0,732 & $-0,14 \%$ & 0,783 & 0,723 & $-7,66 \%$ & 557 & 771 & $38,42 \%$ \\
\hline Paraíso do Norte & 0,733 & 0,754 & $2,86 \%$ & 0,678 & 0,748 & $10,32 \%$ & 2311 & 6558 & $183,77 \%$ \\
\hline Paranacity & 0,764 & 0,730 & $-4,45 \%$ & 0,772 & 0,752 & $-2,59 \%$ & 4805 & 14720 & $206,35 \%$ \\
\hline Paranapoema & 0,735 & 0,733 & $-0,27 \%$ & 0,611 & 0,673 & $10,15 \%$ & 196 & 1499 & $664,80 \%$ \\
\hline
\end{tabular}


TABELA 4 - (CONTINUAÇÃO) CONCENTRAÇÃO FORTE A MUITO FORTE DE POSSE DE TERRA NOS PRINCIPAIS MUNICÍPIOS CANAVIEIROS PARANAENSES, 1995-2006

\begin{tabular}{|c|c|c|c|c|c|c|c|c|c|}
\hline \multirow{2}{*}{ Localidade } & \multicolumn{3}{|c|}{ Índice de Gini } & \multicolumn{3}{|c|}{ Índice de Theil } & \multicolumn{3}{|c|}{ Área plantada (hectare) } \\
\hline & 1995 & 2006 & $\operatorname{Var}(\%)$ & 1995 & 2006 & $\operatorname{Var}(\%)$ & 1995 & 2006 & $\operatorname{Var}(\%)$ \\
\hline Paranavaí & 0,769 & 0,786 & $2,21 \%$ & 0,773 & 0,750 & $-2,98 \%$ & 0 & 1668 & $*$ \\
\hline Pitanga & 0,645 & 0,732 & $13,49 \%$ & 0,622 & 0,745 & $19,77 \%$ & 0 & 500 & $*$ \\
\hline Porecatu & 0,733 & 0,808 & $10,23 \%$ & 0,597 & 0,768 & $28,64 \%$ & 10318 & 9656 & $-6,42 \%$ \\
\hline Presidente Castelo Branco & 0,580 & 0,774 & $33,45 \%$ & 0,598 & 0,728 & $21,74 \%$ & 3464 & 3500 & $1,04 \%$ \\
\hline Quinta do Sol & 0,745 & 0,733 & $-1,61 \%$ & 0,633 & 0,670 & $5,85 \%$ & 272 & 4000 & $1370,59 \%$ \\
\hline Ribeirão do Pinhal & 0,703 & 0,737 & $4,84 \%$ & 0,654 & 0,729 & $11,47 \%$ & 400 & 400 & $0,00 \%$ \\
\hline Santa Fé & 0,630 & 0,714 & $13,33 \%$ & 0,573 & 0,662 & 15 , & 530 & 1477 & 178 \\
\hline Sant & 0,723 & 0,724 & $4 \%$ & 0,653 & 0,658 & $0,77 \%$ & 4000 & 3100 & $-22,50 \%$ \\
\hline o Oeste & 0,698 & 0,719 & $3,01 \%$ & 0,653 & 0,664 & $1,68 \%$ & 10 & 350 & $3400,00 \%$ \\
\hline Sar & 0,747 & 0,751 & $0,54 \%$ & 0,660 & 0,672 & $1,82 \%$ & 0 & 250 & . \\
\hline São Carlos & 0,781 & 0,786 & $0,64 \%$ & 0,740 & 0,725 & $-2,03 \%$ & 5133 & 8803 & $71,50 \%$ \\
\hline São J & 0,704 & 0,754 & $7,10 \%$ & 0,559 & 0,705 & $26,12 \%$ & 557 & 1639 & $194,25 \%$ \\
\hline São Mano & 0,724 & 0,729 & $0,69 \%$ & 0,905 & 0,774 & $-14,48 \%$ & 316 & 718 & $127,22 \%$ \\
\hline São Sebastião da Amoreira & 0,643 & 0,795 & $23,64 \%$ & 0,688 & 0,764 & $11,05 \%$ & 1500 & 1500 & $0,00 \%$ \\
\hline Siqueira Cam & 0,600 & 0,720 & $20,00 \%$ & 0,552 & 0,716 & $29,71 \%$ & 100 & 200 & $100,00 \%$ \\
\hline Tapejara & 0,724 & 0,792 & $9,39 \%$ & 0,632 & 0,762 & $20,57 \%$ & 3100 & 13850 & $346,77 \%$ \\
\hline Terra Boa & 0,690 & 0,717 & $3,91 \%$ & 0,815 & 0,656 & $-19,51 \%$ & 2000 & 1700 & $-15,00 \%$ \\
\hline Tunei & 0,703 & 0,714 & $1,56 \%$ & 0,663 & 0,681 & $2,71 \%$ & 3435 & 9160 & $166,67 \%$ \\
\hline Umuarama & 0,739 & 0,767 & $3,79 \%$ & 0,717 & 0,745 & $3,91 \%$ & 1698 & 4065 & $139,40 \%$ \\
\hline Uniflor & 0,682 & 0,737 & $8,06 \%$ & 0,482 & 0,724 & $50,21 \%$ & 459 & 1267 & $176,03 \%$ \\
\hline Ventania & 0,794 & 0,883 & $11,21 \%$ & 0,773 & 0,915 & $18,37 \%$ & 0 & 300 & $*$ \\
\hline
\end{tabular}

FONTE: Dados básicos do Censo Agropecuário (1995/96 e 2006) e ALCOPAR trabalhados na pesquisa.

NOTA: *Não se aplica quando o município não tinha a cultura inserida em 1995; Em itálico, município que possui usina e/ou destilaria.

Ainda conforme a Tabela 4, verificou-se que 14 municípios não possuem indústrias (Cruzeiro do Oeste, Diamante do Norte, Icaraíma, Itaúna do Sul, Marumbi, Miraselva, Nossa Senhora das Graças, Nova Olímpia, Paraíso do Norte, Presidente Castelo Branco, São Carlos do Ivaí, São João do Caiuá, Tuneiras do Oeste, Uniflor - todos em negrito), representando $26,92 \%$ do total dos municípios sem indústrias instaladas, com participação superior a $30 \%$ da área plantada com a cultura da cana-de-açúcar, variando de 30,27\% a 64,66\% em 2006 e, em relação a 1995 , variando de $7,89 \%$ a $73,27 \%$.

Dentre esses municípios, o de São Carlos do Ivaí destaca-se com a maior participação da área plantada com cana $(64,66 \%)$, em relação à área total plantada do município, possuindo 8.803 ha de área plantada com a cultura de um total de 13.615 ha em 2006. Evidenciou-se um aumento de 3.670 ha em relação a 1995. O município obteve o índice de Gini de 0,781 e o índice de Theil de 0,740 em 1995 e, respectivamente, 0,786 e 0,725 em 2006, apresentando uma variação de 0,64\% no índice de Gini e de -2,03\% no índice de Theil. Pode-se verificar que houve mudança de pouca significância no índice de Gini e no índice de Theil, ou seja, pequena redução na concentração de terras nesse município.

De modo geral, analisando os 141 municípios canavieiros do estado do Paraná, cons- 
tatou-se que 94 tiveram variação do índice de Gini positiva e 47 apresentaram uma redução no índice de Gini, indicando que 66,67\% dos municípios mantiveram ou aumentaram a concentração fundiária e 33,33\% dos municípios apresentaram uma redução de concentração dos estabelecimentos agropecuários que possuem seus dimensionamentos em torno da moda da distribuição.

Em relação ao índice de Theil, 103 municípios obtiveram variação positiva e 36 apresentaram variação negativa da concentração nos grandes estratos de terras. E somente 2 municípios não apresentaram alteração nesse índice.

A área total plantada de cana-de-açúcar, no conjunto dos 141 municípios da análise, obteve um aumento de 182.073 ha, atingindo 427.272 ha em 2006, apresentando uma variação positiva de 74\%. Entretanto, observou-se que 108 municípios aumentaram a área plantada, 15 reduziram, 2 não apresentaram alterações e 16 passaram a integrar os municípios canavieiros, ou seja, não cultivavam a cana-de-açúcar em 1995.

Cumpre dizer que a pujança na economia canavieira do estado do Paraná, no período de abrangência deste estudo, foi notória. Tal fato, evidentemente, contribuiu para o aumento da área plantada com cana, afetando também a concentração da posse de terras nos municípios canavieiros. Para Shikida et al. (2008, p. 64):

[...] para os principais agentes da agroindústria canavieira, este processo de concentração é derivado da situação conjuntural propícia à expansão do capital produtivo, e as maiores unidades produtivas seguem esta tendência porquanto visam a maior rentabilidade possível - que pode ser derivada das economias de escala reais ou pecuniárias. [...] Tal corolário também está ligado ao avanço da competição permitido pela desregulamentação, em que as empresas que aumentaram seu aporte de cana moída estão buscando, via aumento da escala de produção, reduzir custos e ganhar eficiência.

\section{CONSIDERAÇÕES FINAIS}

Este artigo teve como objetivo descrever e analisar a estrutura fundiária nos principais municípios canavieiros em 1995-2006. Para atender ao objetivo proposto, além de pesquisa por levantamento nos Censos Agropecuários de 1995/96 e 2006, coletando informações a respeito da quantidade e do dimensionamento dos estabelecimentos agropecuários e da participação da cultura da cana na área plantada desses municípios, foram utilizados também dois métodos de análise de dados (índices de Gini e Theil), cujo papel foi de mensurar os níveis de concentração fundiária.

O trabalho evidenciou que o setor sucroalcooleiro teve ascensão no Paraná em 19952006. Essa expansão do setor se deu, conforme Schmidtke (2007), Shikida et al. (2008) e Deli- 
berali (2010), pelas condições edafoclimáticas do estado e por questões mercadológicas como a busca crescente pelos combustíveis alternativos aos fósseis (favorecendo a produção e consumo dos biocombustíveis, com destaque para o etanol - que, além disso, teve uma bem sucedida introdução no mercado automobilístico com os veículos flex fued), bem como diante do cenário benéfico para o açúcar, haja vista a competitividade desse produto paranaense e diante das expectativas de possível diminuição do protecionismo no comércio internacional.

Percebeu-se, com este estudo, que a cana-de-açúcar se destaca dentre as cinco principais culturas temporárias no estado no período de análise, em que foi possível observar a cana como a cultura que vem ganhando espaço em área plantada, diferentemente das outras quatro culturas que oscilaram bastante quanto à sua área plantada. Cumpre dizer que a fronteira agrícola do Paraná encontra-se esgotada (DELIBERALI, 2010).

As análises evidenciaram, em 2006, uma concentração forte a muito forte de posses de terras na estrutura fundiária do estado. Essa configuração decorreu do índice de Gini igual a 0,752 e do índice de Theil igual a 0,796, com acréscimo de 1,76\% e 4,19\%, respectivamente, em relação ao início do período (1995).

O trabalho constatou que, dos 141 municípios canavieiros do Paraná, 94 (66,67\%) tiveram uma variação do índice de Gini positiva e 47 (33,33\%) apresentaram uma redução no índice. Em relação ao índice de Theil, 103 (73\%) municípios obtiveram variação positiva, 36 $(25,5 \%)$ apresentaram variação negativa da concentração e 2 (1,4\%) municípios não configuraram modificação nesse índice.

As disparidades entre os índices, evidenciadas pelos percentuais de análise do período, estão relacionadas ao fato, já ressaltado, de que o índice de Theil é mais sensível às configurações na parte superior da distribuição, enquanto o de Gini é mais susceptível às configurações na moda da distribuição.

Destarte, o presente trabalho evidenciou que a atividade sucroalcooleira vem ganhando espaço no estado e que isso ocorre devido aos pontos positivos inerentes à cultura já referidos, provocando uma mudança na pauta agrícola paranaense. Contraposto a esse fato, cabe citar que essa cultura, como as demais culturas temporárias expansionistas, necessita de produção em escala; assim se constatou, seja no curto seja no médio prazo, a permanência de alta concentração fundiária no Paraná.

Não obstante, a rota perseguida por este artigo, embora útil para diagnosticar a estrutura fundiária dos principais municípios canavieiros do Paraná, certamente não encerra as possibilidades metodológicas de investigação sobre o tema. Portanto, sugere-se, como agenda de trabalho, que mais pesquisas possam analisar estes e outros apontamentos sobre a agroindústria 
canavieira paranaense, contribuindo para o rigor desse debate científico.

\section{REFERÊNCIAS}

ALCOPAR. Estatísticas. Disponível em: <http://www.alcopar.org.br/produtos/hist_cana. php>. Acesso em: 1/12/2010.

BACHA, C. J. C. Economia e política agrícola no Brasil.São Paulo: Atlas, 2004.

CÂMARA, L. A concentração da propriedade agrária no Brasil. Boletim Geográfico, Rio de Janeiro, v. 7, n. 77, p. 516-528, 1949.

CONTI, J. B. Clima e meio ambiente. São Paulo: Atual, 1998.

DELIBERALI, E. A. O perfil do desenvolvimento socioeconômico dos municípios paranaenses que possuem agroindústria canavieira: estudos de casos. Dissertação (Mestrado em Desenvolvimento Regional e Agronegócio) - Universidade Estadual do Oeste do Paraná, Toledo, 2010.

HOFFMANN, R. Desigualdade e pobreza. São Paulo: Editora da USP, 1998.

HOFFMANN, R. Estatística para economistas. São Paulo: Editora da USP, 1990.

IBGE. Disponível em: < http://www.ibge.gov.br/home/estatistica/economia/agropecuaria>. Acesso em: 7/12/2010.

IBGE. Censo Agropecuário 1995/1996. Disponível em: <http://www.sidra.ibge.gov.br>. Acesso em: 30/9/2010.

IBGE. Censo Agropecuário 2006. Disponível em: <http://www.sidra.ibge.gov.br>. Acesso em: 30/9/2010.

IPARDES. Estabelecimentos rurais no Paraná crescem, concentração de terras permanece. Disponível em: < http://www.ipardes.gov.br/modules/noticias/article.php?storyid/>. Acesso em: 22/8/2010.

IPARDES. Indicadores de sustentabilidade ambiental por bacias hidrográficas do estado do Paraná. Disponível em: <http://www.ipardes.gov.br/modules/conteudo/>. Acesso em: 22/8/2010.

IPEA. Banco de dados. Disponível em: <http://www.ipeadata.gov.br>. Acesso em: 30/9/2010.

MORISSAWA, M. A história da luta pela terra e o MST. São Paulo: Expressão Popular, 2001.

RISSARDI JR., D. J. A agroindústria canavieira do Paraná pós-desregulamentação: uma abordagem neoschumpeteriana. Dissertação (Mestrado em Desenvolvimento e Agronegócio) - Universidade Estadual do Oeste do Paraná, Toledo, 2005.

SCHMIDTKE, C. R. Expectativas da agroindústria canavieira paranaense diante da diminuição do protecionismo no comércio internacional. Dissertação (Mestrado em Desenvolvimento e Agronegócio) - Universidade Estadual do Oeste do Paraná, Toledo, 2007.

SHIKIDA, P. F. A.; VIAN, C. E. F.; LIMA, R. A. S.; DAHMER, V. S. Concentração na agroindústria canavieira paranaense pós-desregulamentação setorial. Informações Econômicas, São Paulo, v. 38, n. 9, p. 55-67, 2008. 
